\title{
Behavior of concrete beams reinforced with GFRP under transverse force
}

\author{
Igor Gorbunov, Vladimir Kakusha*, Mikhail Moshnikov, Maksim Kudryavtsev \\ and Kristina Dobrina
}

Moscow State University of Civil Engineering, Yaroslavskoe shosse, 26, Moscow, 129337, Russia

\begin{abstract}
The article discusses the effect of transverse reinforcement spacing for the strength and deformation characteristics of beams with glass fibre reinforced polymer. The bending tests results of reinforced concrete specimens are presented (GFRP) with different concrete strength and reinforcement spacing. Force-deflection, force-GFRP bars deformation and force-concrete compressed zone deformation dependencies are given in the article. Based on ultimate force and beams destruction pattern it is established that increasing transverse reinforcement spacing reduces the beams strength and leads to destruction in oblique section. With narrowmashed transverse reinforcement fracture occurs in the compressed zone of concrete. A computational analysis for different types of beams fracture is presented. It is established that transverse reinforcement spacing doesn't affect the parameters determined by service limit state: crack formation load, crack width and beam deflection. A comparative analysis of maximum permissible deflection based on test results and theoretical calculations was carried out. The numerical values of bending stiffness parameter are obtained at the loading stages with linear deformation before and after first crack formation.
\end{abstract}

\section{Introduction}

Glass-fiber reinforced polymer (GFRP) bars market in Russia has increased drastically in the last years. Currently many necessary regulatory documents for GFRP bars and instructions for reinforced with GFRP structure design have been developed and constituted in Russia [1],[2],[3],[4],[5].

Therefore, there is an increase in industrial and civil structures designed with the use of GFRP bars. However, it is not advised to use GFRP as a working reinforcement for bending structures due to lack of experimental data. Nevertheless, it is not wise to neglect tensile properties of GFRP bars. Some Russian and foreign researches of bending elements reinforced with GFRP showed good results [6],[7],[8],[9].

We can achieve economical profit by increasing overhaul period for bending elements in aggressive environments (silage, hopper, highways beams) in case of using GFRP reinforcement. Tests of beams were carried out to get experimental data of real work of concrete elements reinforced with GFRP. According to previous researches, after diagonal

\footnotetext{
* Corresponding author: KakushaVA@mgsu.ru
} 
cracking occurs, deflection of FRP RC beams is significantly greater than the estimated according to Eurocode 2, and the component of shear crack inducted deflection can affect the serviceability [10]. Beams were tested by short-term load in order to achieve fracture from transverse force in oblique section.

\section{Methods}

\subsection{Specimen and reinforcement details}

Fig. 1 shows reinforcement and loading configuration for beams.

Longitudal GFRP bars characteristics:

$-\sigma_{\mathrm{f}}=1148,11 \mathrm{MPa}$;

$-\quad \mathrm{E}_{f}=52619,05 \mathrm{MPa}$;

- $\quad \varepsilon=21819 \cdot 10^{-6}$ strain units;

$-\mathrm{d}_{\text {nom }}=14,69 \mathrm{~mm}$.

Transverse GFRP bars characteristics:

$-\quad \sigma_{\mathrm{f}}=1229,06 \mathrm{MPa}$

- $\mathrm{E}_{f}=63453,43 \mathrm{MPa}$

- $\quad \varepsilon=19369 \cdot 10^{-6}$ strain units.

$-\mathrm{d}_{\text {nom }}=6,07 \mathrm{~mm}$

Table 1 shows concrete characteristics based on cubes tests (100x100x100 mm) according to [11], prisms tests $(100 \times 100 \times 400 \mathrm{~mm})$ for compression according to [12] and prisms tests $(100 \times 100 \times 400 \mathrm{~mm})$ for bending according to [11] in order to estimate axial tension strength.

Table 1. Beam concrete test results

\begin{tabular}{|c|c|c|c|c|}
\hline $\begin{array}{c}\text { Beam } \\
\text { marking* }\end{array}$ & $\begin{array}{c}\text { Compression } \\
\text { concrete } \\
\text { strength R, } \\
\text { MPa }\end{array}$ & $\begin{array}{c}\text { Tension concrete } \\
\text { strength Rb, MPa }\end{array}$ & $\begin{array}{c}\text { Compression } \\
\text { concrete strength for } \\
\text { prism Rb, MPa }\end{array}$ & $\begin{array}{c}\text { Modulus of } \\
\text { elasticity Eb, } \\
\text { MPa }\end{array}$ \\
\hline B3.14.50.1 & 31,99 & 1,92 & 24,95 & 25631 \\
\hline B3.14.50.2 & 32,50 & 2,07 & 25,35 & 26038 \\
\hline B3.14.50.3 & 32,66 & 2,11 & 25,48 & 26167 \\
\hline B3.14.100.1 & 32,20 & 1,98 & 25,12 & 25798 \\
\hline B3.14.100.2 & 52,51 & 2,50 & 44,54 & 32432 \\
\hline B3.14.100.3 & 52,87 & 2,51 & 44,91 & 32704 \\
\hline B3.14.150.1 & 31,65 & 1,89 & 24,69 & 25354 \\
\hline B3.14.150.2 & 32,48 & 2,03 & 25,33 & 26019 \\
\hline B3.14.150.3 & 32,64 & 2,05 & 25,46 & 26149 \\
\hline
\end{tabular}

* the first letter of the marking means the type of structure («B3» - beam). The second number of the marking means the diameter of longitudal bars in $\mathrm{mm}$. The third number of the marking means the spacing in transverse reinforcement $(50 \mathrm{~mm}, 100 \mathrm{~mm}$ and 150 $\mathrm{mm})$. The last number means serial number. 


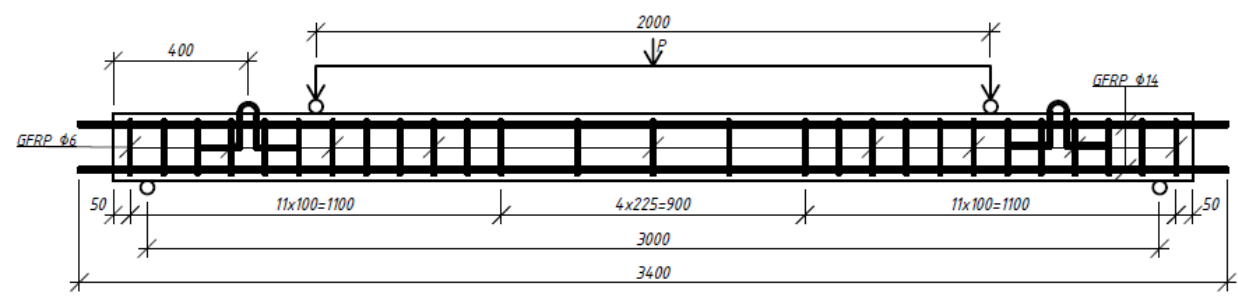

Fig. 1. Reinforcement and loading configuration of beams (spacing in transverse reinforcement $100 \mathrm{~mm}$ ).

Beams have dimensions of 100x200x3200 mm.

\subsection{Experimental program}

Beam for short-term load were tested inside MTS equipment which consists of rearranging power frame CFM Schiller, controller FlexTest-60 and hydrocylinder MTS 201.30T.

Displacement indicators Mircon IC-50-0,01 with a range of 0-50 $\mathrm{mm}$ and division value of $0,01 \mathrm{~mm}$ were used to measure deflection.

Ultrasonic pulse method with the help of «Pulsar 1.2» and piezoelectric converters with a frequency of $65 \mathrm{kHz}$ was used to estimate crack formation process.

Concrete and GFRP deformations were registered via multichannel measurement complex National Instruments based on NI PXIe-1075. Strain gages with the base of $1 \mathrm{~mm}$ (TML FLA-1-11) were used for GFRP, with the base of $60 \mathrm{~mm}$ and $120 \mathrm{~mm}$ (TML PL 6011, TML PL-120-11) - for concrete.

Strain gages layout is shown on figure 2. Piezoelectric converters layout is shown on figure 3 .

Concrete cubes and prisms were tested on test machine Instron 1000 HDX.

Crack formation process was also controlled visually with the help of Brinell microscope MPB-2.

The beams were loaded step by step:

- before crack formation - load step was 2,0 kN, loading speed was 1,0 kN/min, hold time at each step was 5 min;

- after crack formation till load reaches $18,0 \mathrm{kN}$ - load step was 4,0 kN, loading speed was $6,0 \mathrm{kN} / \mathrm{min}$, hold time at each step was $5 \mathrm{~min}$;

- after load reaches $18,0 \mathrm{kN}$ till fracture - load step was $12,0 \mathrm{kN}$, loading speed was 6,0 $\mathrm{kN} / \mathrm{min}$, hold time at each step was $5 \mathrm{~min}$.

Following measurements were carried out at each step during hold time:

- load and displacement of hydrocylinder,

- deflection of beam, deformation of strain gages;

- ultrasonic speed between control points;

- visual examination of the beam and crack recording (fig. 14-15).

Four transmitter-reciever (T-R) routes for ultrasonic oscillations (USO) controlled normal and oblique crack formation and development along the beam. 


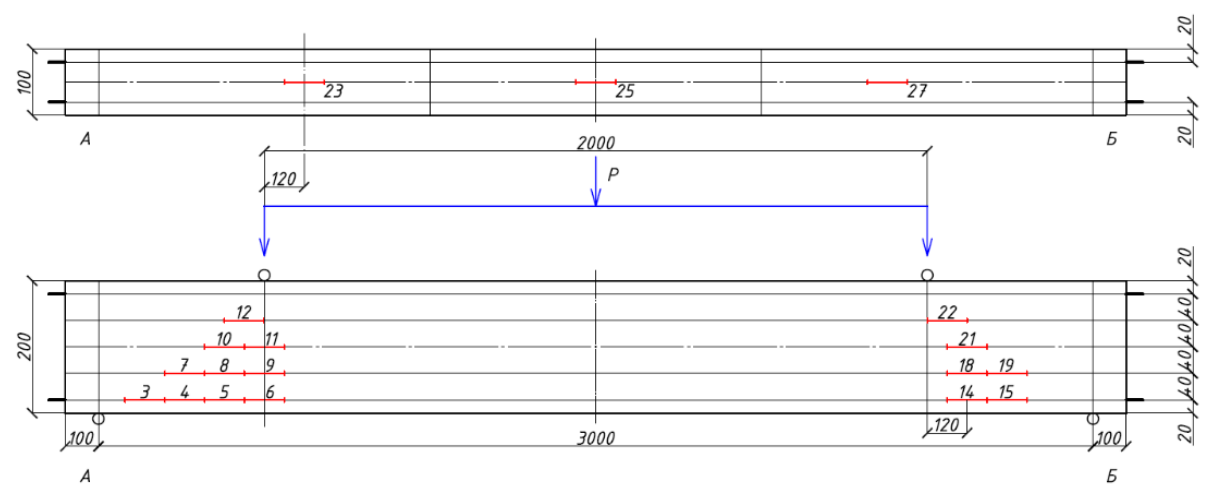

Fig. 2. Strain gages layout

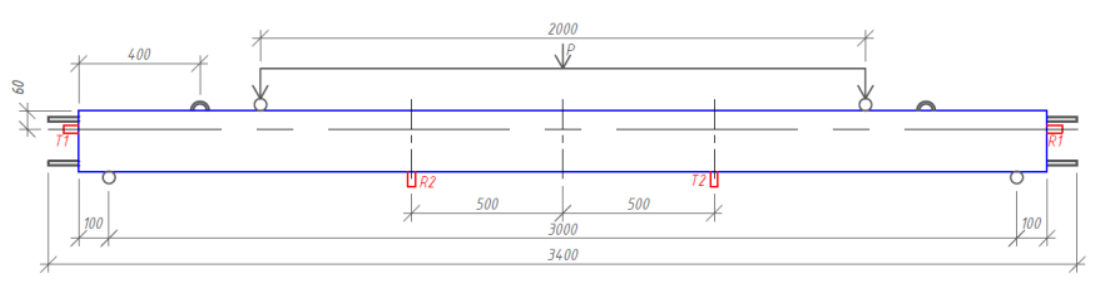

Fig. 3. Ultrasonic converters layout

\section{Results}

\subsection{Displacements and deformations measurements}

Deflection charts for two deformation segments are shown on fig. 4-6. Displacements in the first segment before crack formation should correspond with theoretical deflections from bending moment. Only one beam from each test series is shown in this chapter because beams inside the series have corresponding deflection measurement data.

Strain gages data correspond with stress-strain behavior of beam according to deflection data (fig. 7-12).

\subsection{Ultrasonic measurements}

Crack formation in beams B3.14.50.1-B3.14.50.3 was detected by short routes (T1-R2, T2-R1, T2-R2) on the loading step from 4 to $6 \mathrm{kN}$. Crack developing in concrete through the GFRP bars and active formation of oblique cracks was seen on chart for oblique routes with load changing from 8 to $30 \mathrm{kN}$. Increase in crack width in the pure bending zone with the slowdown of oblique crack growth was registered with load changing from 42 to $90 \mathrm{kN}$.

The beam B3.14.100.3 was characteristic in the beam series B3.14.100.1-B3.14.100.3 based on USO data. Microcracks formation in the pure bending zone was registered on the loading step from 2 to $4 \mathrm{kN}$. After that, active hair cracks formation was seen that slowed down when the load reached $30 \mathrm{kN}$. Active oblique cracks formation started at $8 \mathrm{kN}$ based on USO data from routes T1-R2 and T2-R1.

For beams B3.14.150.1-B3.14.150.3 there was a unified crack formation and developing image based on USO data. Microcracks formation was registered on the loading 
step from 4 to $6 \mathrm{kN}$ and continued till the load reached $20 \mathrm{kN}$. After that there was a slowdown in developing of hair and mainstream cracks (fig. 13).

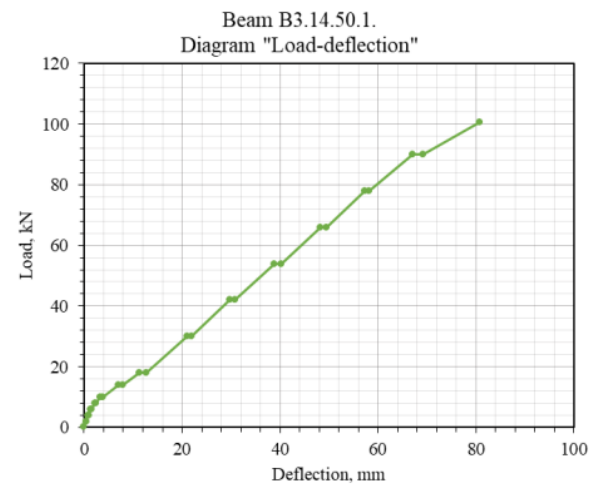

Fig. 4. Diagram «Load-deflection» for beam B3.14.50.1

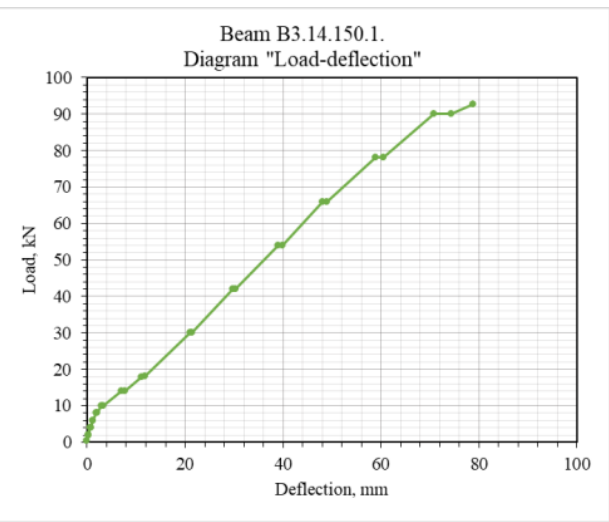

Fig. 6. Diagram «Load-deflection» for beam B3.14.150.1

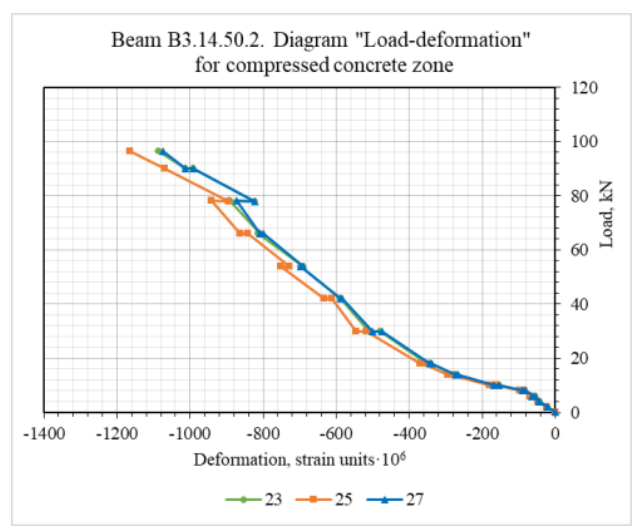

Fig. 8. Diagram «Load-deformation» for compressed concrete zone for beam B3.14.50.2

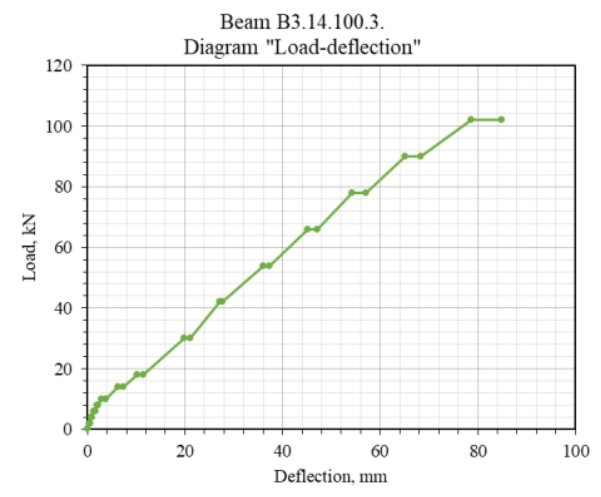

Fig. 5. Diagram «Load-deflection» for beam B3.14.100.3

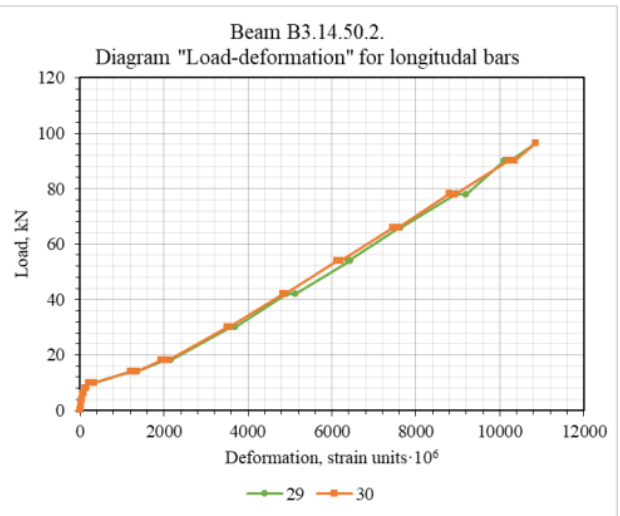

Fig. 7. Diagram «Load-deformation» for longitudal bars for beam B3.14.50.2

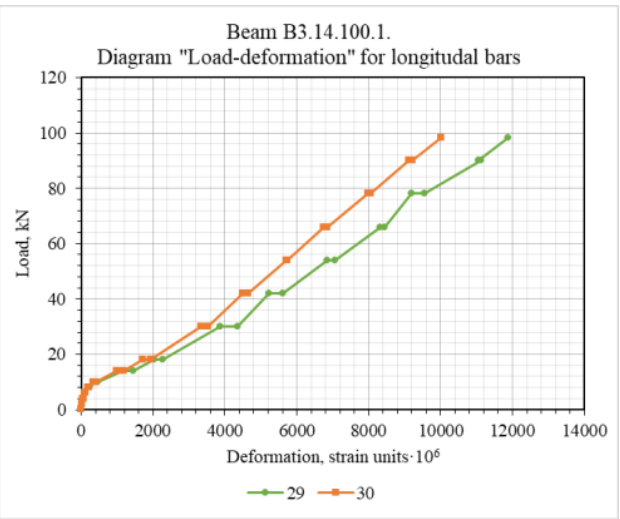

Fig. 9. Diagram «Load-deformation» for longitudal bars for beam B33.14.100.1 


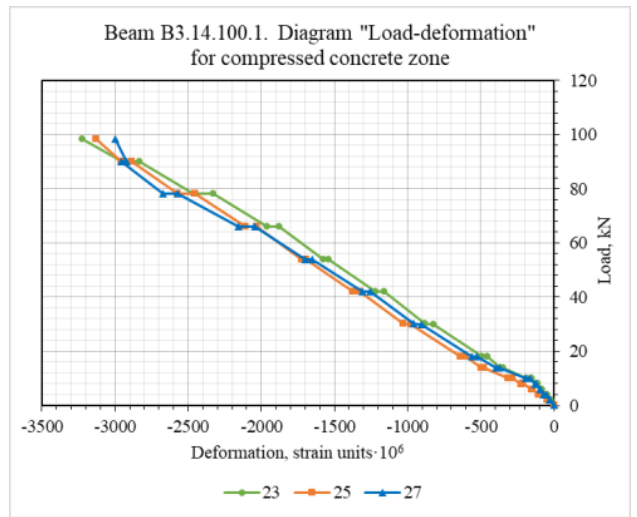

Fig. 10. Diagram «Load-deformation» for compressed concrete zone for beam B3.14.100.1

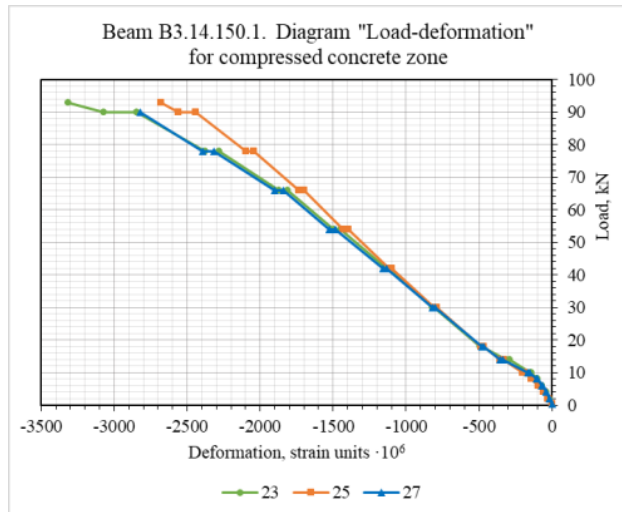

Fig. 12. Diagram «Load-deformation» for compressed concrete zone for beam B3.14.150.1

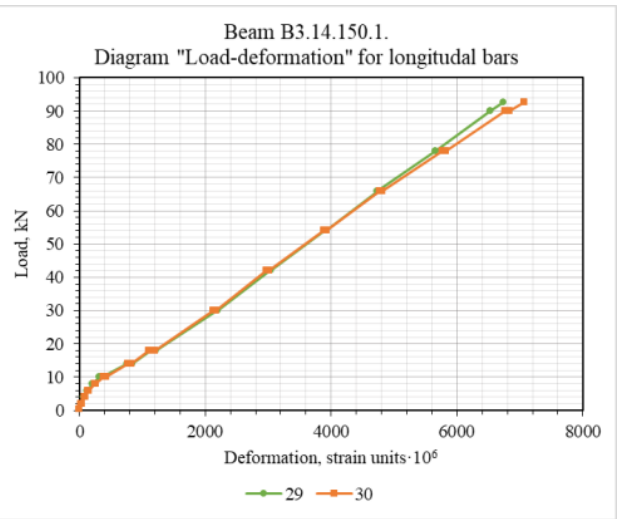

Fig. 11. Diagram «Load-deformation» for longitudal bars for beam B3.14.150.1

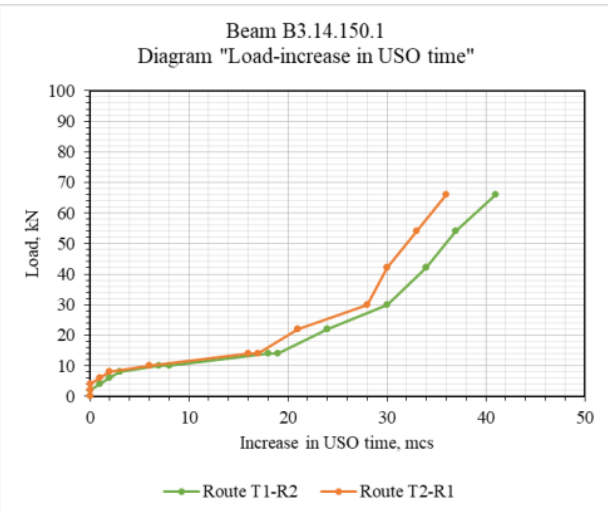

Fig. 13. Diagram «Load-increase in USO time» for beam B3.14.150.1

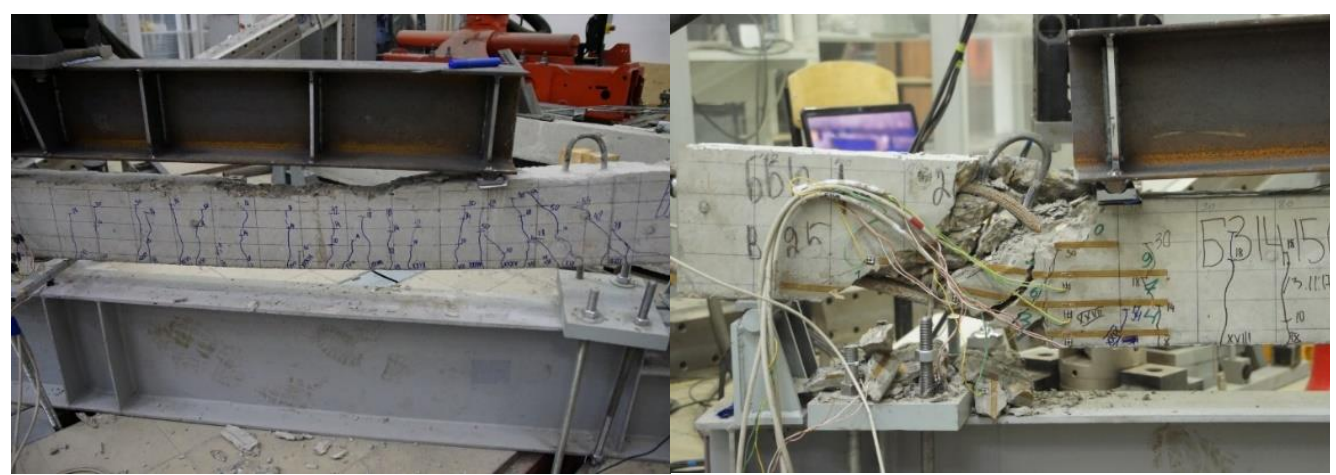

Fig. 14. Beam B3.14.50.3 fracture behavior from bending moment $\left(\mathrm{P}_{\mathrm{u}}=95,49 \mathrm{kN}\right)$
Fig. 15. Beam B3.14.150.1 fracture behavior from shear force $\left(\mathrm{P}_{\mathrm{u}}=92,76 \mathrm{kH}\right)$ 


\section{Discussion}

\subsection{Comparison of the mid-span deflection}

Theoretical deflection for beam B3.14.50.1 from bending moment per $1 \mathrm{kN}$ of external force:

$$
f_{T}=\frac{13 \cdot l^{3}}{1296 \cdot E J^{\prime}}
$$

where: $E=2563,1 \mathrm{kN} \cdot \mathrm{cm}^{2}$ - concrete modulus of elasticity for beam B3.14.50.1;

$l=300 \mathrm{~cm}-$ beam span;

$$
J=\frac{b \cdot h^{3}}{12}=\frac{10 \cdot 20^{3}}{12}=6667 \mathrm{~cm}^{4}
$$

$E J=2563,1 \cdot 6667=1709 \cdot 10^{4} \mathrm{kN} \cdot \mathrm{cm}^{2}-$ bending stiffness;

$$
\mathrm{f}_{T, I}=\frac{13 \cdot 1 \cdot 3^{3} \cdot 10^{6}}{1296 \cdot 1709 \cdot 10^{4}}=0,16 \mathrm{~mm} \text {. }
$$

Experimental deflection (fig. 4) at load of $6 \mathrm{kN}$ excluding holds was $f \mathrm{e}=1,3 \mathrm{~mm}$, which corresponds to deflection per $1 \mathrm{kN}: f_{\mathrm{e}, \mathrm{I}}=0,22 \mathrm{~mm}>0,16 \mathrm{~mm}$. Difference between experimental and theoretical deflections is $27 \%$, but taking into account difference in tangent modulus of elasticity and modulus determined on the «middle» deformation segment we can say about almost complete convergence for determining the deflection via experiment and calculation.

On the main linear segment of beam deformation with cracks in the load range from 18 to $90 \mathrm{kN}$ deflection changed from 11,2 to $69,3 \mathrm{~mm}$. Deflection per $1 \mathrm{kN}$ was:

$$
\mathrm{f}_{e, I I}=\frac{69,3-11,2}{90,0-18,0}=0,81 \mathrm{~mm}
$$

Bending stiffness $\mathrm{B}$ on the second deformation segment is a formal integral characteristic that is regarded as an inseparable composition of physical and geometrical parameters. This deflection values is corresponded by formal bending stiffness of:

$$
B=J_{I I}=E J \cdot \frac{f_{e, I}}{f_{e, I I}}=2563 \cdot 6667 \cdot \frac{0,22}{0,81}=462 \cdot 10^{4} \mathrm{kN} \cdot \mathrm{cm}^{2}
$$

Bending stiffness is 3,7 times less than on the first segment of linear deformation.

Concrete modulus of elasticity for beams B.3.14.100.2 and B.3.14.100.3 is higher compared to beam series B3.14.50. For beam B3.14.100.3 on the first linear deformation segment with loading up to $6 \mathrm{kN}$ deflection was $f_{\mathrm{e}}=0,8 \mathrm{~mm}$ (excluding deflection on holds), which corresponds with deflection per $1 \mathrm{kN}$ of $f_{e, I}=0,13 \mathrm{~mm}$.

In the load range from 14 to $78 \mathrm{kN}$ deflection increased from 7,3 to $54,3 \mathrm{~mm}$ (fig. 5), which corresponds with deflection per $1 \mathrm{kN}$ of:

$$
\mathrm{f}_{e, I I}=\frac{54,3-7,3}{78,0-14,0}=0,73 \mathrm{~mm}
$$

During linear deformation of beams with cracks deflection per $1 \mathrm{kN}$ increased 5,6 times which corresponds with stiffness $B$ :

$$
B=\frac{3270 * 6667}{5,6}=389 \cdot 10^{4} \mathrm{kN} \cdot \mathrm{cm}^{2}
$$

For beams with 50 and $100 \mathrm{~mm}$ spacing in transverse reinforcement fracture occurred in the pure bending zone from bending moment. For beams with $150 \mathrm{~mm}$ spacing in transverse reinforcement fracture occurred from shear force in the oblique section.

For beam B3.14.150.1 with the increase in load from $0,34 \mathrm{kN}$ to 6,00 deflection was 1,0 $\mathrm{mm}$ (excluding deflection on holds) which corresponds with deflection per $1 \mathrm{kN}$ of $f_{\mathrm{e}, \mathrm{I}}=$ $0,18 \mathrm{~mm}$.

With the small increase in modulus of elasticity comparing to beam B3.14.50.1, difference in deflection can be explained by methodical error in measurements on small load values. 
In the segment of linear deformation with cracks in the load range from 10,0 to $90,0 \mathrm{kN}$ deflection increased by $67,7 \mathrm{~mm}$, which corresponds with deflection per $1 \mathrm{kN}$ of $f \mathrm{e}, \mathrm{II}=$ $0,85 \mathrm{~mm}$.

Stiffness B in the deformation segment with cracks:

$$
B=2580 \cdot 6667 \cdot \frac{0,18}{0,85}=366 \cdot 10^{4} \mathrm{kN} \cdot \mathrm{cm}^{2}
$$

Thus, it was established that transverse reinforcement spacing doesn't influence beam deflections on all stages of deformation. Experimental deflection values have good convergence with theoretical.

\subsection{Bending moment calculation results}

It was established that for beams with transverse reinforcement spacing of 50 and 100 $\mathrm{mm}$ tension deformations in the longitudal GFRP bars in the limit state is almost equal. (fig. 7, 9). Internal moments in the normal section for beams B3.14.50.1 and B3.14.100.1 calculated using GFRP bars deformation and ultimate compression stress in concrete differ negligibly (5\%) from moments from external load. Herewith, load margin in GFRP bars by $50 \%$ predetermined fracture of these beams in compressed concrete zone.

\subsection{Shear force calculation}

Elastic and strength characteristics of concrete and GFRP bars were acquired during specimens tests (table 1).

Calculation by concrete band between oblique section of beam B3.14.50.1 with the lowest prism strength of $\mathrm{R}_{\mathrm{b}}=24,95 \mathrm{MPa}$ is shown.

$$
Q=\varphi_{b_{1}} \cdot R_{b} \cdot b \cdot h_{0}=0,3 \cdot 2,495 \cdot 10 \cdot 17,3=129,5 k N
$$

Shear force from external load:

Calculation by oblique section:

$$
Q_{\text {int }}=\frac{100,49}{2}=50,25 k N<129,5 k N
$$

Concrete axial tension strength $R_{b t}=1,92 \mathrm{MPa}$;

Tension strength of transverse reinforcement bars: $R_{f}=1229 \mathrm{MPa}$;

Modulus of elasticity: $E=63453 \mathrm{MPa}$;

Cross-section area for diameter of $6,07 \mathrm{~mm}:-A=\frac{2 \cdot \pi \cdot d^{2}}{4}=0,578 \mathrm{~cm}^{2}$.

Shear force taken by concrete:

$$
Q_{b_{\text {min }}}=\varphi_{b r} \cdot R_{b t} \cdot b \cdot h_{0} \cdot \frac{h_{0}}{c}=1,5 \cdot 0,192 \cdot 10 \cdot 17,3 \cdot \frac{17,3}{45}=19,4 k N,
$$

where: $\mathrm{C}$ - projected length of oblique crack, $\mathrm{C}=45 \mathrm{~cm}$.

where $\mathrm{C}=17,3 \mathrm{~cm}$.

$$
Q_{b_{\max }}=1,5 \cdot 0,192 \cdot 10 \cdot 17,3=50,4 \mathrm{kN}
$$

Shear force taken by transverse reinforcement with a spacing of $S_{w}=50 \mathrm{~mm}$ :

where $R_{f w}=0,004 \cdot E$

$$
Q_{f w}=\varphi_{f w} \cdot \frac{R_{f w} \cdot A_{f w}}{S_{w}} \cdot C
$$

Maximum shear force:

with $C=45 \mathrm{~cm}$;

$$
Q_{f w_{\max }}=0,75 \cdot 0,004 \cdot 6345,3 \cdot \frac{0,578 \cdot 45}{5}=98,8 \mathrm{kN}
$$

Maximum shear force:

with $C=17,3 \mathrm{~cm}$.

$$
Q_{f w_{\text {min }}}=0,75 \cdot 0,004 \cdot 6345,3 \cdot \frac{0,578 \cdot 17,3}{5}=38,0 \mathrm{kN}
$$




$$
\begin{aligned}
& Q=Q_{b_{\text {min }}}+Q_{f w_{\max }}=19,4+98,8=118,2 k N>50,25 k N \\
& Q=Q_{b_{\text {max }}}+Q_{f w_{\text {min }}}=50,4+38,0=88,4 k N>50,25 k N
\end{aligned}
$$

Thus, possible values of ultimate shear force in the section is more than shear force from external load and the main fracture factor is bending moment.

Test results show that fracture of three beams with transverse reinforcement spacing of $100 \mathrm{~mm}$ occurred in the pure bending zone concrete from bending moment.

Calculation of shear force taken by concrete and transverse reinforcement is made for beam B3.14.100.1 with the lowest concrete strength.

Concrete compression prism strength $R_{b}=25,12 \mathrm{MPa}$;

Concrete modulus of elasticity $E=25798 \mathrm{MPa}$;

Concrete axial tension strength $R_{b t}=1,98 \mathrm{M \Pi а}$

$h_{0}=17,3 \mathrm{~cm}$.

Transverse reinforcement characteristics are shown during calculations for beam B3.14.50.1.

Shear force taken by concrete:

Minimal $Q_{b_{\text {min }}}$ with projection length C $=35 \mathrm{~mm}$ :

$$
\begin{gathered}
Q_{b_{\text {min }}}=\varphi_{b r} \cdot R_{b t} \cdot b \cdot h_{0} \cdot \frac{h_{0}}{C}=1,5 \cdot 0,198 \cdot 10 \cdot 17,3 \cdot \frac{17,3}{35}=25,4 k N \\
\text { Maximum } Q_{b_{\max }} \text { with } C=h_{0}: \\
Q_{b_{\max }}=1,5 \cdot 0,198 \cdot 10 \cdot 17,3=51,4 \mathrm{kN}
\end{gathered}
$$

Shear force taken by transverse reinforcement:

Maximum with $C=35 \mathrm{~cm}$ :

$$
Q_{f w_{\max }}=\varphi_{f w} \cdot \frac{R_{f w} \cdot A_{f w}}{S_{w}} \cdot C
$$

Minimum with $C=h_{0}$ :

$$
Q_{f w_{\max }}=0,75 \cdot 0,004 \cdot 6345,3 \cdot \frac{0,578 \cdot 35}{10}=38,4 \mathrm{kN}
$$

$$
Q_{f w_{\min }}=0,75 \cdot 0,004 \cdot 6345,3 \cdot \frac{0,578 \cdot 17,3}{10}=19,0 \mathrm{kN}
$$

Shear force from maximum external load:

Two combination of internal forces:

$$
Q_{e x}=\frac{98,15}{2}=49,1 \mathrm{kN}
$$

$$
\begin{aligned}
& Q=Q_{b_{\text {min }}}+Q_{f w_{\text {max }}}=25,4+38,4=63,8 k N>49,1 k N \\
& Q=Q_{b_{\text {max }}}+Q_{f w_{\text {min }}}=51,4+19,0=70,4 k N>49,1 k N
\end{aligned}
$$

Beam fracture at maximum load of $98,15 \mathrm{kN}$ occurred from bending moment.

Fracture of beams with transverse reinforcement spacing of $S_{w}=150 \mathrm{~mm}$ occurred by oblique section with a projection length of 300-400 $\mathrm{mm}$.

Two variants of projection lengths $\left(C=350 \mathrm{~mm}\right.$ and $\left.\mathrm{C}=\mathrm{h}_{0}=173 \mathrm{~mm}\right)$ for beam B3.14.150.3 were checked in shear force calculations.

Shear force taken by concrete with projection length $\mathrm{C}=350 \mathrm{~mm}$ :

$$
Q_{b}=1,5 \cdot 0,205 \cdot 10 \cdot 17,3 \cdot \frac{17,3}{35}=26,3 \mathrm{kN}
$$

Ultimate shear force for transverse reinforcement:

$$
Q_{f w_{\text {max }}}=0,75 \cdot 0,004 \cdot 6345,3 \cdot \frac{0,578 \cdot 35}{15}=25,7 \mathrm{kN}
$$

Ultimate shear force taken by concrete with a projection length of $C=h_{0}$ :

$$
Q_{b}=1,5 \cdot 0,205 \cdot 10 \cdot 17,3=53,2 \mathrm{kN}
$$

Ultimate shear force taken by transverse reinforcement:

$$
Q_{f w}=0,75 \cdot 0,004 \cdot 6345,3 \cdot \frac{0,578 \cdot 17,3}{15}=12,7 \mathrm{kN}
$$

Total shear force with projection length of $C=350 \mathrm{~mm}$ is lower than in the case of oblique crack with $45^{\circ}$ angle.

Minimal shear force in oblique section: 
Shear force from external load:

$$
Q_{b}+Q_{f w}=26,3+25,7=52 k N
$$

$$
Q_{e x}=\frac{99,6}{2}=49,8 k N \approx 52 k N
$$

Thus, load bearing capacity of oblique sections corresponds with shear force from external load.

\section{Conclusions}

1. Beam fracture with $50 \mathrm{~mm}$ spacing in transverse reinforcement occurred in concrete in the pure bending zone at average load of $\mathrm{P}_{\mathrm{u}}=97,5 \mathrm{kN}$.

2. Beam fracture with $100 \mathrm{~mm}$ spacing in transverse reinforcement occurred in concrete in the pure bending zone except for beam B3.14.100.2 which fractured in concrete under the loading beam support. The average ultimate load value for 3 beams is $\mathrm{P}_{\mathrm{u}}=100,6 \mathrm{kN}$.

3. Beam fracture with $150 \mathrm{~mm}$ spacing in transverse reinforcement occurred in oblique section from shear force. The average ultimate load value for 3 beams is $\mathrm{P}_{\mathrm{u}}=94,2 \mathrm{kN}$.

4. Crack formation loads were:

- $\quad$ for beams with longitudal GFRP Ø14 with $50 \mathrm{~mm}$ spacing in transverse reinfocement $\mathrm{P}_{\mathrm{cr}}=0,10 \cdot \mathrm{P}_{\mathrm{u}}$;

- $\quad$ for beams with longitudal GFRP Ø14 with $100 \mathrm{~mm}$ spacing in transverse reinfocement $\mathrm{P}_{\mathrm{cr}}=0,08 \cdot \mathrm{P}_{\mathrm{u}}$;

- for beams with longitudal GFRP Ø14 with $150 \mathrm{~mm}$ spacing in transverse reinfocement $\mathrm{P}_{\mathrm{cr}}=0,09 \cdot \mathrm{P}_{\mathrm{u}}$;

5. Crack formation was gradual based on USO and visual control data: at first there was abrupt increase in cracks length with a corresponding increase in cracks width and then there was only increase in crack width (with stable length of cracks) in the load range from $0,3-0,5 \mathrm{P}_{\mathrm{u}}$ to $\mathrm{P}_{\mathrm{u}}$.

6. Theoretical deflection calculated using initial geometric section characteristic and concrete and GFRP modulus of elasticity is lower than experimental by $10 \%$ average based on deflection measurement in the initial linear loading stages.

7. Main work of beam during loading was during crack developing, elastic tension of GFRP bars and almost linear increase in deflection. On this stage bending stiffness compared to initial is :

- $\quad 3,7$ times lower for beam with $50 \mathrm{~mm}$ spacing in transverse reinfocement and equals $B=462 \cdot 10^{4} \mathrm{kN} \cdot \mathrm{cm}^{2}$;

- 5,6 times lower for beam with $100 \mathrm{~mm}$ spacing in t ransverse reinfocement and equals $B=389 \cdot 10^{4} \mathrm{kN} \cdot \mathrm{cm}^{2}$;

- $\quad$ 4,7 times lower for beam with $150 \mathrm{~mm}$ spacing in transverse reinfocement and equals $B=366 \cdot 10^{4} \mathrm{kN} \cdot \mathrm{cm}^{2}$.

This research was supported by The Head Regional Shared Research Facilities of the Moscow State University of Civil Engineering.

\section{References}

1. GOST 31938-2012 Fibre-reinforced polymer bar for concrete reinforcement. General specifications (2014). 
2. SP 295.1325800.2017 Concrete structures reinforced with fibre-reinforced polymer bars. Design rules (2018).

3. GOST 32486-2013 Polymer composite frame for reinforcement of concrete structures. Methods for determination of durability characteristics (2013).

4. GOST 32487-2013 Polymer composite frame for reinforcement of concrete structures. Methods for determination of characteristics of resistance to the corrosive media (2013).

5. GOST 32492-2013 Fiber-reinforced polymer bar for concrete reinforcement. Determination of physical-mechanical properties (2013).

6. A.D. Rakhmonov, N.P. Solov'ev, V.M. Pozdeev, Vestnik MGSU, 1, 187-195 (2014).

7. V.F. Stepanova, F.Yu. Stepanov, PGS, 1, 45-47 (2013).

8. S.A. Madatiyan, PGS, 9, 16-19 (2002).

9. A.E. Lapshinov, A.G. Tamrazyan, Stroitel'stvo i rekonstrukciya, 4(78), 20-30 (2018).

10. T. Imjai, M. Guadagnini, K. Pilakoutas, FPRRCS 8, 11-14 (2007).

11. GOST 10180-2012 Concretes. Methods for strength determination using reference specimens (2013).

12. GOST 24452-80 Concretes. Methods of prismatic, compressive strength, modulus of elasticity and Poisson's ratio determination (1982). 